\title{
Non-surgical treatment of transverse deficiency in adults using Microimplant-assisted Rapid Palatal Expansion (MARPE)
}

\author{
Daniel Paludo Brunetto¹, Eduardo Franzzotti Sant'Anna², Andre Wilson Machado³, Won Moon ${ }^{4}$
}

DOI: http://dx.doi.org/10.1590/2177-6709.22.1.110-125.sar

Introduction: Maxillary transverse deficiency is a highly prevalent malocclusion present in all age groups, from primary to permanent dentition. If not treated on time, it can aggravate and evolve to a more complex malocclusion, hindering facial growth and development. Aside from the occlusal consequences, the deficiency can bring about serious respiratory problems as well, due to the consequent nasal constriction usually associated. In growing patients, this condition can be easily handled with a conventional rapid palatal expansion. However, mature patients are frequently subjected to a more invasive procedure, the surgically-assisted rapid palatal expansion (SARPE). More recently, researches have demonstrated that it is possible to expand the maxilla in grown patients without performing osteotomies, but using microimplants anchorage instead. This novel technique is called microimplant-assisted rapid palatal expansion (MARPE). Objective: The aim of the present article was to demonstrate and discuss a MARPE technique developed by Dr. Won Moon and colleagues at University of California - Los Angeles (UCLA). Methods: All laboratory and clinical steps needed for its correct execution are thoroughly described. For better comprehension, a mature patient case is reported, detailing all the treatment progress and results obtained. Conclusion: It was concluded that the demonstrated technique could be an interesting alternative to SARPE in the majority of non-growing patients with maxillary transverse deficiency. The present patient showed important occlusal and respiratory benefits following the procedure, without requiring any surgical intervention.

Keywords: Microimplant-assisted Rapid Palatal Expansion. Palatal expansion technique. Polysomnography. Obstructive Sleep Apnea Syndrome. Adult patients. Maxillary transverse deficiency. Posterior crossbite.

Introdução: a deficiência transversa da maxila é uma má oclusão com alta prevalência em todas as faixas etárias, da dentição decídua à permanente. Se não for corrigida, pode agravar-se com o passar do tempo, prejudicando o crescimento e desenvolvimento facial. Além dos prejuízos oclusais, essa deficiência pode trazer problemas respiratórios também severos, devido à consequente constrição da cavidade nasal. Em pacientes em crescimento, a sua resolução é relativamente simples, por meio da expansão rápida convencional da maxila. Porém, os pacientes já maduros geralmente são encaminhados para um procedimento mais invasivo, a expansão rápida de maxila assistida cirurgicamente (SARPE). Mais recentemente, pesquisadores têm demonstrado que é possível executar a expansão palatal esquelética em pacientes adultos sem auxílio de osteotomias, mas sim com auxílio de mini-implantes. Essa técnica é denominada Microimplant-Assisted Rapid Palatal Expansion, ou MARPE. Objetivo: o objetivo do presente artigo é demonstrar e discutir uma das técnicas disponíveis de MARPE, desenvolvida por Won Moon e colaboradores, na University of California, Los Angeles (UCLA). Métodos: a técnica encontra-se detalhadamente descrita, com as etapas laboratoriais e clínicas que devem ser seguidas para sua correta execução. Para descrevê-la, é apresentado o caso clínico de uma paciente adulta, detalhando toda a sequência do tratamento e os resultados obtidos. Conclusão: a técnica apresentada pode ser uma alternativa não invasiva à SARPE na resolução da deficiência transversa de maxila, podendo ser empregada na maioria dos pacientes com crescimento facial finalizado. A paciente apresentada demonstrou benefícios significativos nos aspectos oclusal e respiratório, sem a necessidade de intervenção cirúrgica.

Palavras-chave: Expansão rápida da maxila assistida por mini-implantes. Técnica de expansão palatina. Polissonografia. Síndrome da apneia obstrutiva do sono. Pacientes adultos. Deficiência transversa de maxila. Mordida cruzada posterior.

${ }^{1}$ Post-graduation Professor of Orthodontics, Universidade Federal do Paraná, Dental School, Department of Restorative Dentistry, Curitiba/PR, Brazil. ${ }^{2}$ Associate Professor, Universidade Federal do Rio de Janeiro, Dental School, Department of Pediatric Dentistry and Orthodontics, Rio de Janeiro/RJ, Brazil.

${ }^{3}$ Adjunct Professor, Universidade Federal da Bahia, Dental School, Department of Orthodontics, Salvador/BA, Brazil.

${ }^{4}$ Associate Professor, University of California, Los Angeles, Dental School, Orthodontics Area, Los Angeles/CA, EUA.

Contact address: Daniel Paludo Brunetto

Av. Sete de Setembro 4456, Curitiba/PR, Brasil - CEP: 80.250-210

E-mail: daniel_brunetto@hotmail
How to cite this article: Brunetto DP, Sant'Anna EF, Machado AW, Moon W. Non-surgical treatment of transverse deficiency in adults using Microimplant-assisted Rapid Palatal Expansion (MARPE). Dental Press J Orthod. 2017 Jan-Feb;22(1):110-25.

DOI: http://dx.doi.org/10.1590/2176-9451.22.1.110-125.sar

Submitted: September 06, 2016

Revised and accepted: October 10, 2016

» The authors report no commercial, proprietary or financial interest in the products or companies described in this article.

» Patients displayed in this article previously approved the use of their facial and intraoral photographs. 


\section{INTRODUCTION}

The prevalence of transverse maxillary deficiency, which affects an important number of patients seeking orthodontic care, may reach $23.3 \%$ within the primary dentition population. ${ }^{1}$ This type of malocclusion usually develops during facial growth and development and, if left untreated, will probably affect the permanent dentition, since the chances of spontaneous correction are low. Some of the most prevalent factors on its multifactorial etiology are myofunctional disorders of the stomatognathic system, usually associated with deleterious habits such as thumb sucking. ${ }^{2,3}$ In these cases, the tongue may be in an abnormally lower position, which leaves room for the antagonist muscles (buccinators) to apply dominant forces and consequently constrict the maxillary arch. Intramembranous maxillary bone formation may be affected by and depends on surrounding muscles activity and individual breathing pattern along development. ${ }^{4,5}$

At the same time, genetic and hereditary factors may determine the development of maxillary transverse deficiencies. Typical cases are those of patients with Class III malocclusion with mandibular prognathism, in which P561T polymorphism in the GHR candidate gene, responsible for growth hormone receptors, for instance, determines the excessive growth on condylar cartilage. ${ }^{6}$ As a result, maxillary and mandibular posterior teeth may present with increased overjet as the mandible is protruded (Fig 1).

If not properly managed within appropriate time, maxillary transverse deficiency, associated or not with posterior crossbite, may result in several problems for the patient: different degrees of occlusal disharmony; changes in tongue posture; damage to periodontal structures, such as local bone loss and gingival recession; functional shift of the mandible due to incorrect buccolingual tipping of posterior teeth; asymmetric mandibular position in growing patients; joint disorders and muscle function disturbances; lack of space in the arch for adequate dental alignment. ${ }^{7,8,9}$ The most serious consequence of maxillary transverse deficiency, however, might be the consequent narrowing of the nasal cavity, which increases nasal air resistance (Fig 2) and may be an etiological factor of obstructive sleep apnea syndrome (OSAS). ${ }^{10,11}$

For the treatment of this condition, according to orthodontic consensus, patients should undergo rap- id palatal expansion (RPE) immediately, while still growing. This procedure has been used for over a century in orthodontics, and its positive effects have been widely described and documented. ${ }^{12-15}$ The earlier the treatment is delivered, the better the prognosis and the outcomes, increasing chances of morphological and functional correction and bringing about proper facial development. During primary and mixed dentition and the first years of permanent dentition, RPE is a simple procedure with high success rates. A recent review of the literature showed that it is a stable procedure in the short and long term, regardless of the type of expander used. ${ }^{16}$

Patient growth leads to progressive calcification and interdigitation of craniofacial sutures, including the midpalatal suture, and RPE becomes more difficult as facial growth approaches its completion because of increased mechanical resistance of these structures. ${ }^{17,18}$ The amount of undesired orthodontic movement (buccal tipping of anchor teeth) and its side effects are proportional to patient age and skeletal maturation. Therefore, adolescents tend to have greater tooth inclination and buccal bone dehiscence and, therefore, less orthopedic expansion than children. ${ }^{19,20}$

The procedure becomes even more complex for young adults. Although retrospective case series have demonstrated the success of tooth-borne expansion in this age group, ${ }^{21,22}$ no well-designed clinical trials have determined its success rate. This treatment, therefore, may be classified as unpredictable and of high biological risk. A higher rate of side effects, such as a reduction in alveolar bone thickness and height, bone dehiscence and gingival recession, may be expected as a result of important mechanical forces delivered at the teeth and its supporting structures. Therefore, surgically-assisted rapid palatal expansion (SARPE) is often indicated to these patients. This procedure increases expansion predictability and success, and reduces its side effects. ${ }^{23}$ One of the available SARPE techniques consists of a LeFort I osteotomy associated with surgical rupture of the midpalatal suture, which decrease the mechanical resistance to the lateral forces that will be applied by Hyrax expanders, usually anchored to the first molars and first premolars. However, despite its benefits, SARPE increases biological and financial costs of the treatment. The surgery requires hospitalization and 


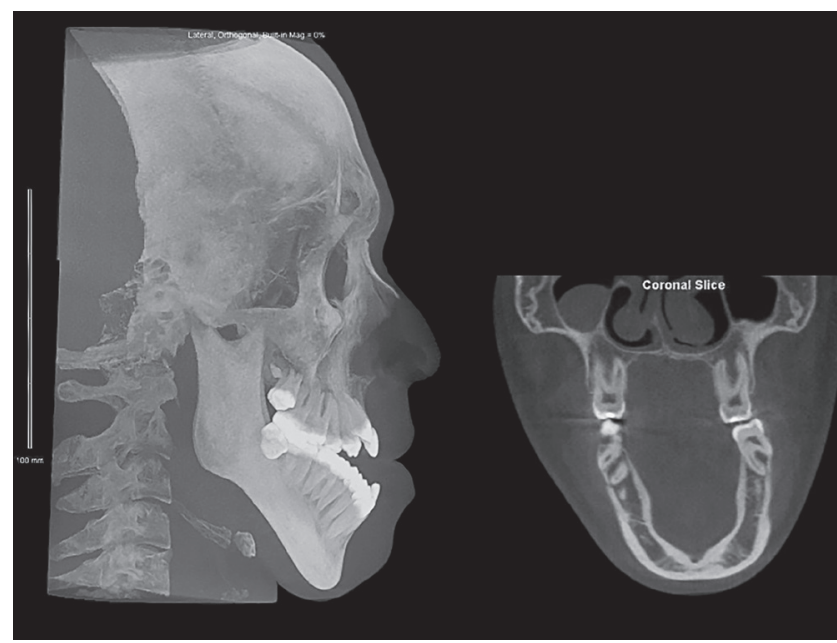

Figure 1 - Lateral radiograph and coronal CBCT slice of a patient with true mandibular prognathism and excessive vertical growth; images show bilateral skeletal posterior crossbite due to mandibular anterior position and lower tongue posture.

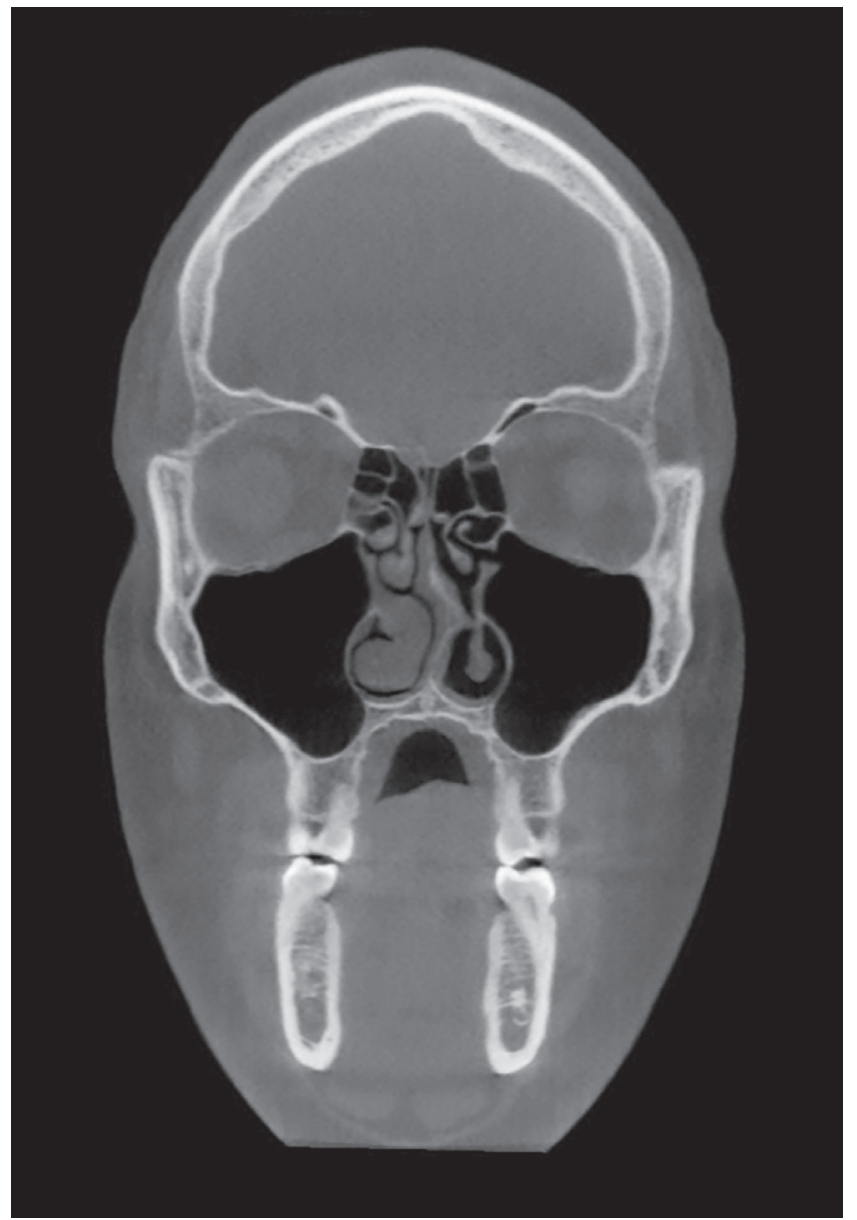

Figure 2 - Coronal slice shows maxillary transverse deficiency and, consequently, nasal cavity narrowing in adult mouth-breather with moderate OSAS (AHI = 15.9). Are also noticeable the high-arched palate, low tongue position and anatomic disorders of nasal cavity (turbinate hypertrophy and septal deviation). general anesthesia, which might scare patients away from surgical-orthodontic treatment for good. ${ }^{21}$

In face of that, some authors have investigated the use of orthodontic microimplants as auxiliary anchorage devices to optimize the application of mechanical forces to circummaxillary sutures, thus avoiding the otherwise indispensable osteotomies. ${ }^{24}$ This system, which has been called microimplant-assisted rapid palatal expansion (MARPE), applies forces to the microimplants, and not to the teeth or periodontium. Different appliance designs and techniques have been described in the literature, and each leads to specific associated outcomes. A recent clinical study using one of them found an $86.96 \%$ success rate in young adult patients (mean age $=20.9 \pm 2.9$ years), with stable results after 30 months of follow-up. ${ }^{25}$

The objective of the present study was to describe one of the techniques available for rapid palatal expansion of non-growing patients, Maxillary Skeletal Expansion (MSE), developed and improved along several years by Dr. Won Moon and colleagues at the University of California - Los Angeles (UCLA). For didactic reasons, this article has been divided into the following sections: introduction; laboratory and clinical procedures, demonstrating the step-by-step manufacture and appliance delivery; case report, to illustrate some of the technique applications; discussion; and conclusion.

\section{LABORATORY AND CLINICAL PROCEDURES}

The laboratory manufacture of the MSE appliance is similar to that of a conventional Hyrax expander. The steps below should be followed:

»First visit: Thorough explanation of procedures to the patient, clarifying all details and technical limitations and reasserting that failure may occur; placement of separator elastics on the permanent maxillary first molars.

"Second visit: Removal of separators, prophylaxis and band placement on first molars; conventional alginate transfer impression; regular plaster pouring; separators elastics placed again on molars; orthodontic accessories (tubes and brackets) may be soldered to the bands at this stage.

$»$ Laboratory procedures (Fig 3): Selection of 8, 10 or $12 \mathrm{~mm}$ MSE, according to palate width (details below); bending wires to reach the bands, following palate curvature, at a separation of at least $2 \mathrm{~mm}$ along all 
their extension; wire soldering to the bands, followed by finishing and polishing; reverse traction hooks may be soldered to the buccal aspect of bands at this stage.

$»$ Third visit (Fig 4): Removal of separators, prophylaxis and expander proof; application of topical anesthetics to the palate; appliance cementing, checking the vertical position in relation to palate; local infiltrative anesthesia; self-drilling microimplant placement using appropriate digital key (Biomaterials Korea $^{\circledR}$, Seoul, South Korea); immediate expander activation (2 to 3 turns); instructions about hygiene and activation; prescription of analgesic drug of choice for two days (optional); no need for antibiotic coverage if the patient has good general health.

"Follow-up: The patient should be seen more often than in conventional expansion. In some cases, the patient is not able to activate the expander at home due to increased resistance, and the professional support is necessary. At all visits, the distance of the expander from the mucosa should be checked. In case of contact, tissue inflammation develops rapidly compromising appliance removal. The stability of all MI should be checked regularly using tweezers and, in case any mobility is found, MI should be removed; the treatment may continue, although extracarefully, even if there is only one MI on each side. ${ }^{25}$

"Removal: For removal, the same connector used for placement, coupled with the digital key, should be slowly turned counterclockwise. Plaque may accumulate on the MI head, which hinders MI gripping (careful previous cleaning of the site is required). Due to the forces applied, MI tipping may occur and complicate the gripping. In most cases, the MI may be removed without anesthesia. Immediately after each MI is removed, a cotton pellet soaked in hydrogen peroxide might be applied to the site to promote asepsis, but no additional care is required. Mucosa wounds usually heal in two to three days after removal. MI should be discarded after removal, and should never be sterilized or reused.

The selected expander should be the one with the greatest expansion capacity that, at the same time, may be kept at an ideal vertical distance from the palatal mucosa. Bicortical anchorage (oral and nasal) is determinant of success and if the expander is too distant from the mucosa (more than $2 \mathrm{~mm}$ ), microimplants may not reach the nasal cortical bone. Moreover, chances of MI deformation are higher if the force is applied too far from the implant/bone interface (Fig 5). The body of the expander should be placed as posterior as possible, close to the junction of hard and soft palate (hard palate mucosa is whiter). The greatest resistance against suture opening is located in the sutures between maxilla and pterygoid plates (Fig 6), and forces should be applied more posteriorly to overcome initial resistance and promote parallel opening of the midpalatal suture (Fig 7). When forces are applied directly into the center of resistance of the maxilla by means of MI, and not to teeth (as in conventional expansion), the force system is more favorable due to a homogeneous force dissipation, ${ }^{26}$ which prevents buccal tipping and produces a more parallel suture opening (Fig 8). ${ }^{27}$

A small amount of anesthetics (no more than 1/4 of a cartridge) may be applied only once on each side, between the two ipsilateral MI. Anesthetic application local should be carefully chosen, and the needle should always be placed close to the midpalatal suture to avoid contact with the palatine artery. The operator should have extensive knowledge of the position of this artery, which may vary according to palate depth. ${ }^{28}$ Whenever possible, a vasoconstrictor combined with the anesthetic should be used to reduce bleeding, which is often absent.

MI should be placed carefully, although the guides (expander holes) facilitates its placement. MI should be as perpendicular as possible to the palatal bone (each MI parallel to all others) so that the force distribution is effective. Therefore, both the anteroposterior and the lateral inclination should be repeatedly checked during placement. When placing the posterior MI, patient should keep the mouth wide open to avoid changing their anteroposterior inclination (MI tend to distal tipping). MI can be delivered in most patients without previous bone perforation, using the digital key. If torque is excessively high, bone perforation can be made using a $1 \mathrm{~mm}$ diameter drill.

A very high-arched and deep palate, typical of chronic mouth-breathers, may hinder the vertical positioning of the MSE. For these patients, the anterior or posterior segments of the expander can be trimmed so that the expander can be placed closer to the mucosa (Fig 9). This option is acceptable because forces are applied to the MI, leaving to teeth only a supporting purpose during MI placement. 

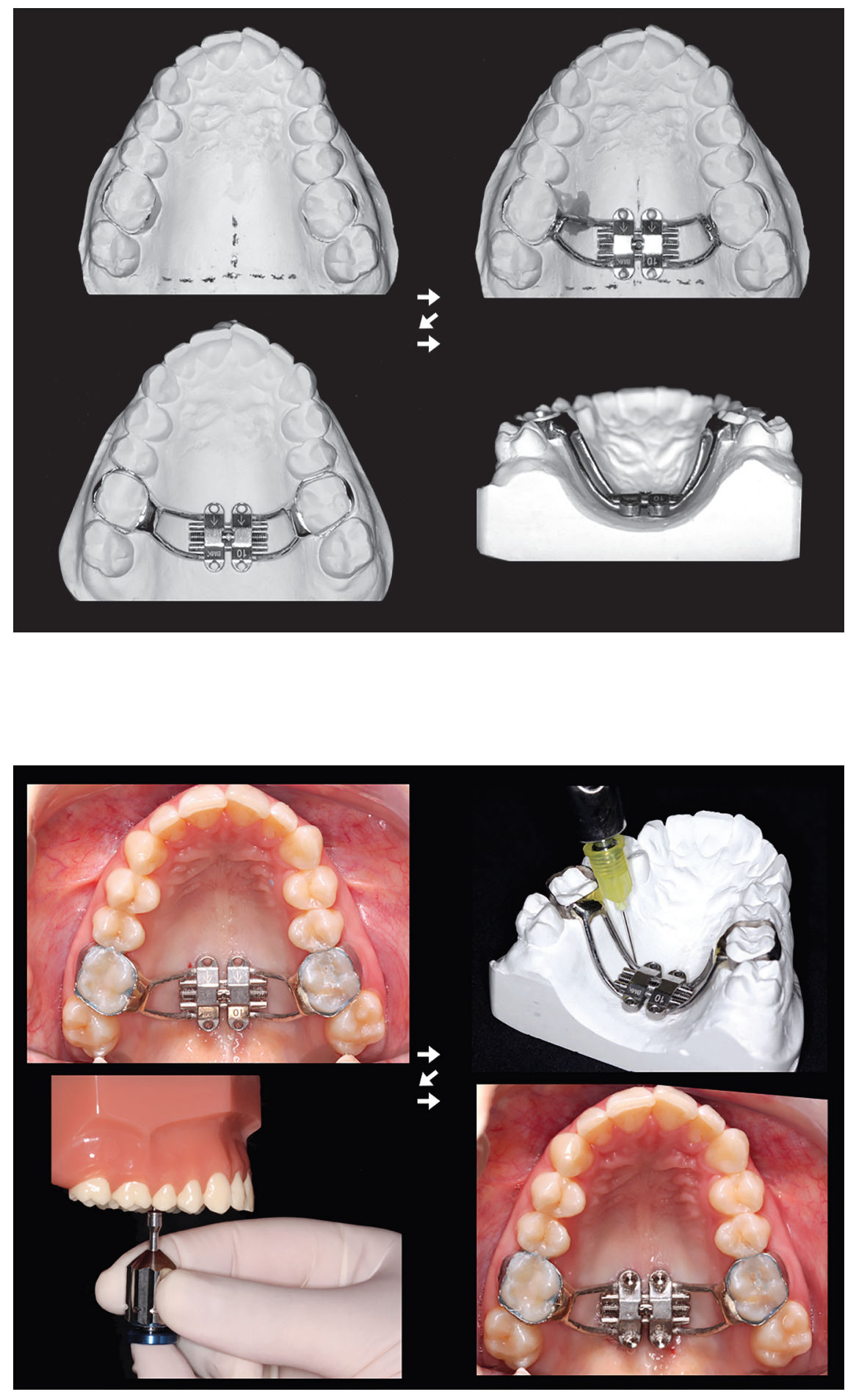

Figure 3 - Laboratory procedures: midline (palatal raphe) and limit between soft and hard palate (clinically determined) traced using lead pencil on model; selection of MSE with greatest expansion capacity (8,10 or $12 \mathrm{~mm}$ ) that can be placed flush to palatal mucosa; appliance wire segments bended to outline palate curvature, holding at least a $2 \mathrm{~mm}$ gap from the mucosa; expander should be centralized to palatal raphe and placed at the most posterior position possible, slightly before limit between soft and hard palate; soldering of wire segments onto the bands, followed by polishing; posterior view shows that expander is flush to palatal mucosa, but should not touch it.

Figure 4 - Clinical visit: Expander clinical proof, topical anesthesia applied, and expander cemented; after expander is cemented (as shown on plas ter model, for teaching purposes), infiltrative anes thesia is applied close to orifices of $\mathrm{Ml}$; after region is anesthetized, $\mathrm{MI}$ are placed paying special attention to anteroposterior and lateral inclination Most cases do not need previous perforation. In dex finger of one hand should hold the digital key, and index and thumb of other hand firmly moves key counterclockwise. During posterior MI placement, patient mouth should be wide open to ensure correct anteroposterior inclination. MI should touch expander gently and not push it toward the mucosa. After the four MI are placed, initial stability is tested using clinical tweezers. After confirmation, expander is activated two to three times.

Although there are no randomized clinical trials, the following activation protocol is suggested as a reference, based on a sample of over 100 patients seen over 15 years (Table 1). In adults, activation may be reduced to once a day after interincisor space appears. Patient's biotype and treatment objectives should be regarded when determining the ideal protocol. The authors recommend giving the patient a paper form to control activations. The $8 \mathrm{~mm}$ MSE has 40 activations (0.2 mm per turn); the $10 \mathrm{~mm}$ one, 50 activations; and the $12 \mathrm{~mm}$ one, 60 activations. Activations should not reach the limit, because the expander loses rigidity as it approaches the limit and might undergo some deformation. 


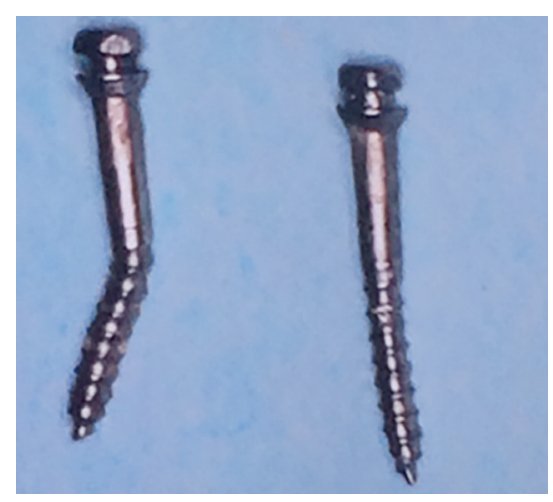

Figure 5 - Force application too far from bone/microimplant interface, resulting in MI deformation.
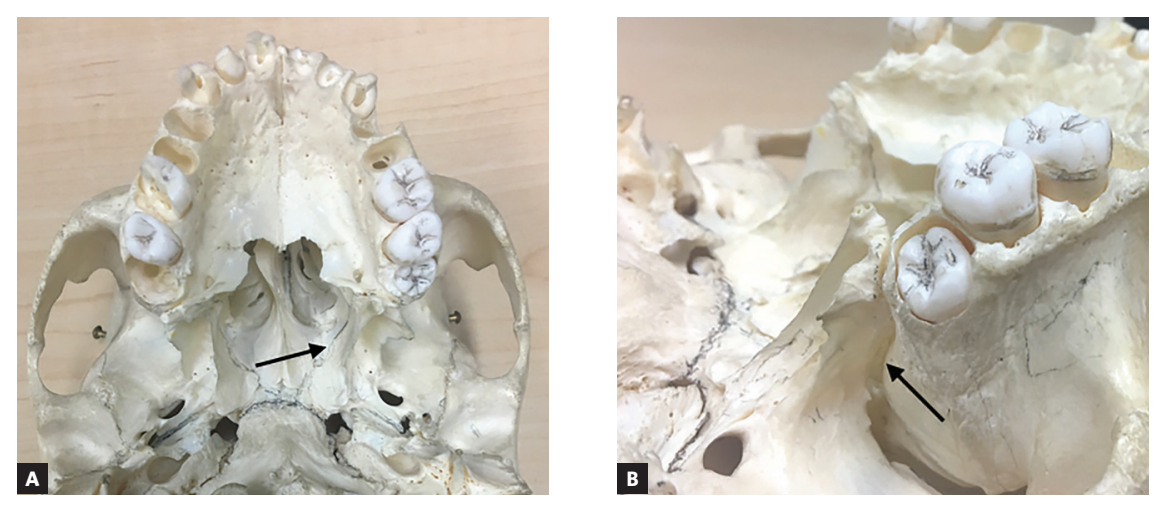

Figure 6 - Dry skull shows relation between the pterygoid plates of sphenoid bone and maxilla. These structures provide great resistance to lateral forces applied by the expander, and connection between them has to be split apart for real skeletal expansion.
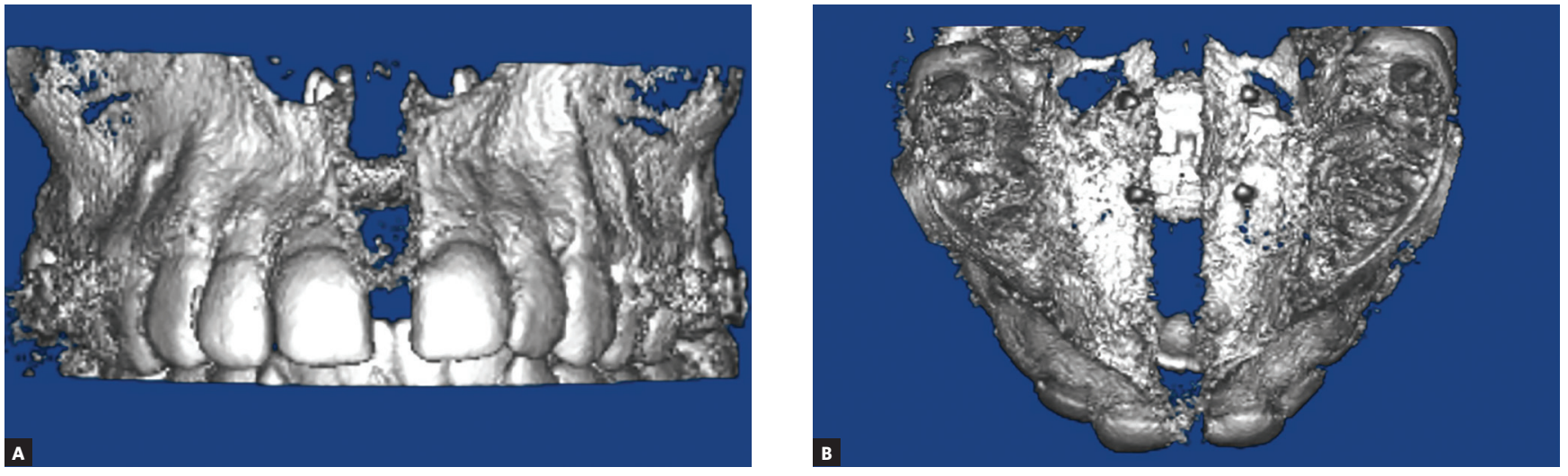

Figure 7 - When expander is placed at a more posterior position, forces concentrate closer to the pterygoid plates, structures that offer great resistance to palatal expansion. Therefore, occurs a parallel opening of the palatine suture anteroposteriorly and vertically, differently from conventional expansion, in which opening takes the form of a "V" (broader in anterior region).
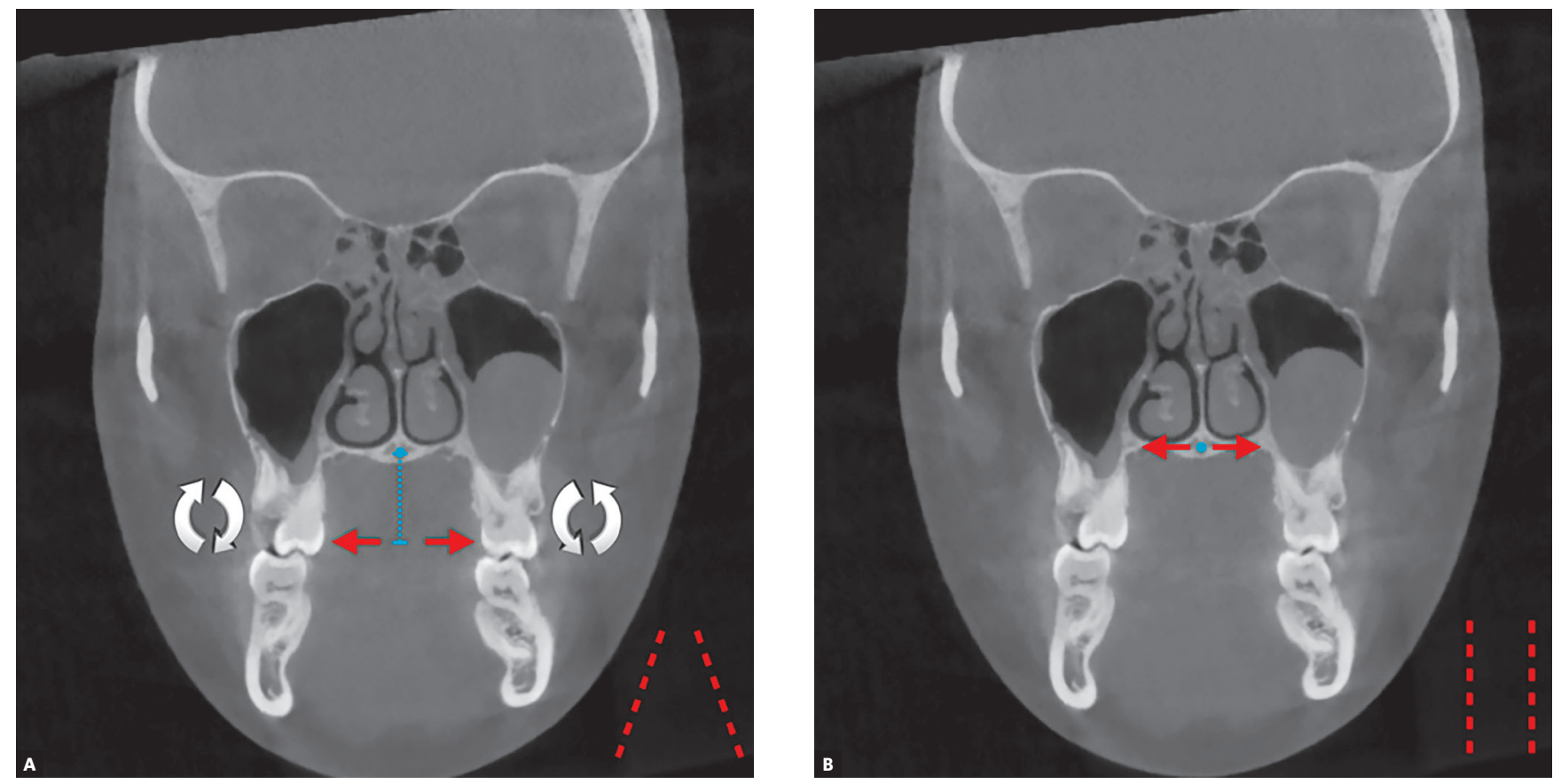

Figure 8 - A) In conventional palatal expansion, forces are applied to teeth, below the center of resistance of the maxilla. This system of forces generates buccal dentoalveolar tipping and an inverted-V opening (coronal view), indicated by the red dotted lines. The amount of momentum generated is directly associated with palatal depth. B) in MARPE, forces are applied directly into the maxillary center of resistance by means of the MI, which practically eliminates inclination forces of posterior teeth and promotes more parallel suture opening in a coronal view (indicated by red dotted lines). 


\section{CASE REPORT}

A 22-year and 6-month-old female was seen for orthodontic treatment at the Orthodontic Clinic of the Universidade Federal do Paraná, Brazil. Her chief complaint was posterior crossbite and deficient breathing, especially during sleep. The patient had not undergone any orthodontic treatment before, but had already made up her mind to avoid maxillary expansion surgery.

Facial examination revealed a harmonic profile and proportional facial thirds. The smiling photo showed excessive buccal corridor display and easily noticeable transverse maxillary deficiency (Fig 10). The mandibular arch had moderate anterior and posterior crowding and left transverse asymmetry due to the posterior crossbite on that side. In the maxillary arch, there was mild crowding and transverse asymmetry (opposite to the mandibular arch) on the left side as well, due to the same crossbite (Fig 11). It was also found microdontic maxillary lateral incisors and right maxillary midline shift. Right molars and canines displayed a Class I relationship, bearing normal horizontal and vertical overjet. On the left side, canines had an edge-to-edge relationship (Class II), with posterior crossbite (Fig 12). Lateral radiograph showed a good skeletal relationship, as well as good inclination and position of maxillary and mandibular incisors (Fig 13). A coronal CBCT slice revealed exacerbated inclination of teeth (torque) in posterior crossbite (Fig 14). Sagittal slices of the joints revealed that the condyles were not centrally positioned in the fossa, which confirmed the clinically present double-bite (Fig 15). Because of her breathing complaints, it was applied the Epworth Sleepiness Scale and Quebec Sleep Questionnaire as screening tools, which revealed a high risk of obstructive sleep apnea syndrome (OSAS). Therefore, the patient underwent in-home polysomnography (Nox Medical, Reykjavik, Iceland), and results revealed an apnea/hypopnea index (AHI) of 7.9, classified as mild apnea syndrome according to the American Association of Sleep Medicine guideline, ${ }^{29}$ associated with moderate snoring and isolated episodes of bruxism (Fig 16).

The first treatment option was non-surgical rapid palatal expansion (MARPE) because the patient refused to have SARPE. We thought skeletal expansion was necessary because of the patient's re-
Table 1 - Suggested activation protocol.

\begin{tabular}{|cc|}
\hline AGE GROUP & ACTIVATION \\
\hline Beginning of adolescence & 3 to $4 \times /$ week \\
\hline End of adolescence & $1 \times /$ day \\
\hline Young adults & $2 x /$ day \\
\hline Older than 25 years & $2 x$ or + /day \\
\hline
\end{tabular}

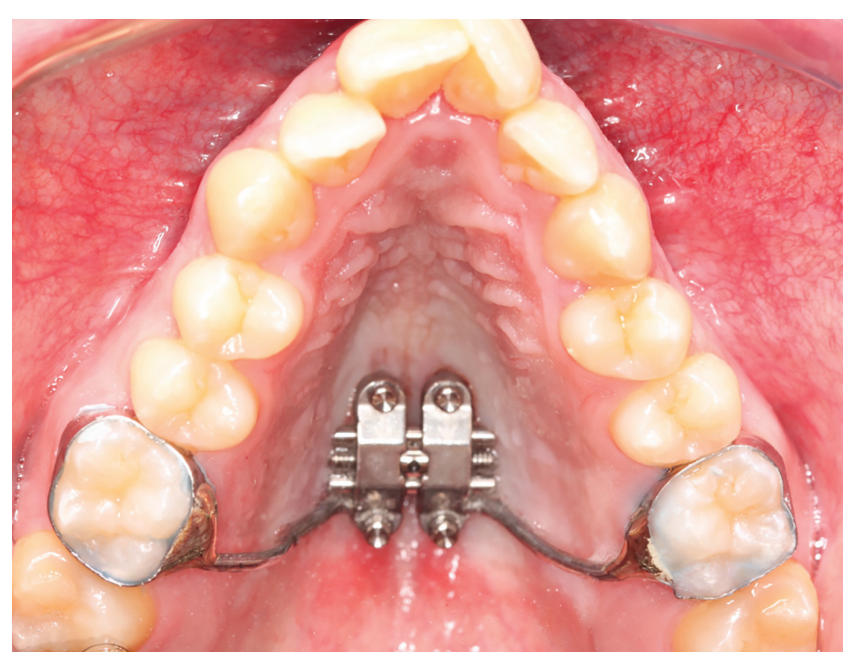

Figure 9 - Maxillary occlusal photograph showing removal of anterior wire seg ments of MSE, to improve vertical fit in a very narrow and high-arched palate.

spiratory disorder, reported by the patient herself at first, and later confirmed by the polysomnography. Treatment alternative consisted of fixed orthodontic appliance and microimplants for intrusion and buccal inclination of the left maxillary posterior teeth to compensate the buccolingual inclination of teeth in crossbite area, with possible future side effects on its supporting structures.

Treatment started with the placement of a $10 \mathrm{~mm}$ maxillary skeletal expander (MSE) and three immediate activations (1/4 of a turn, 90 degrees each), followed by two daily activations. By the second week, the patient reported having heard clicks in the region of the palatal suture and, in the following days, appearance of the interincisal diastema (Fig 17). There was a discrete opening of the anterior bite due to contact of the buccal cuspid of the left first maxillary molar, which moved in the direction of overlapping the antagonist mandibular molar. Photographs after 34 activations confirmed suture opening and lack of collateral buccal inclination of maxillary molars (Fig 18). The patient often needed help to perform the activa- 

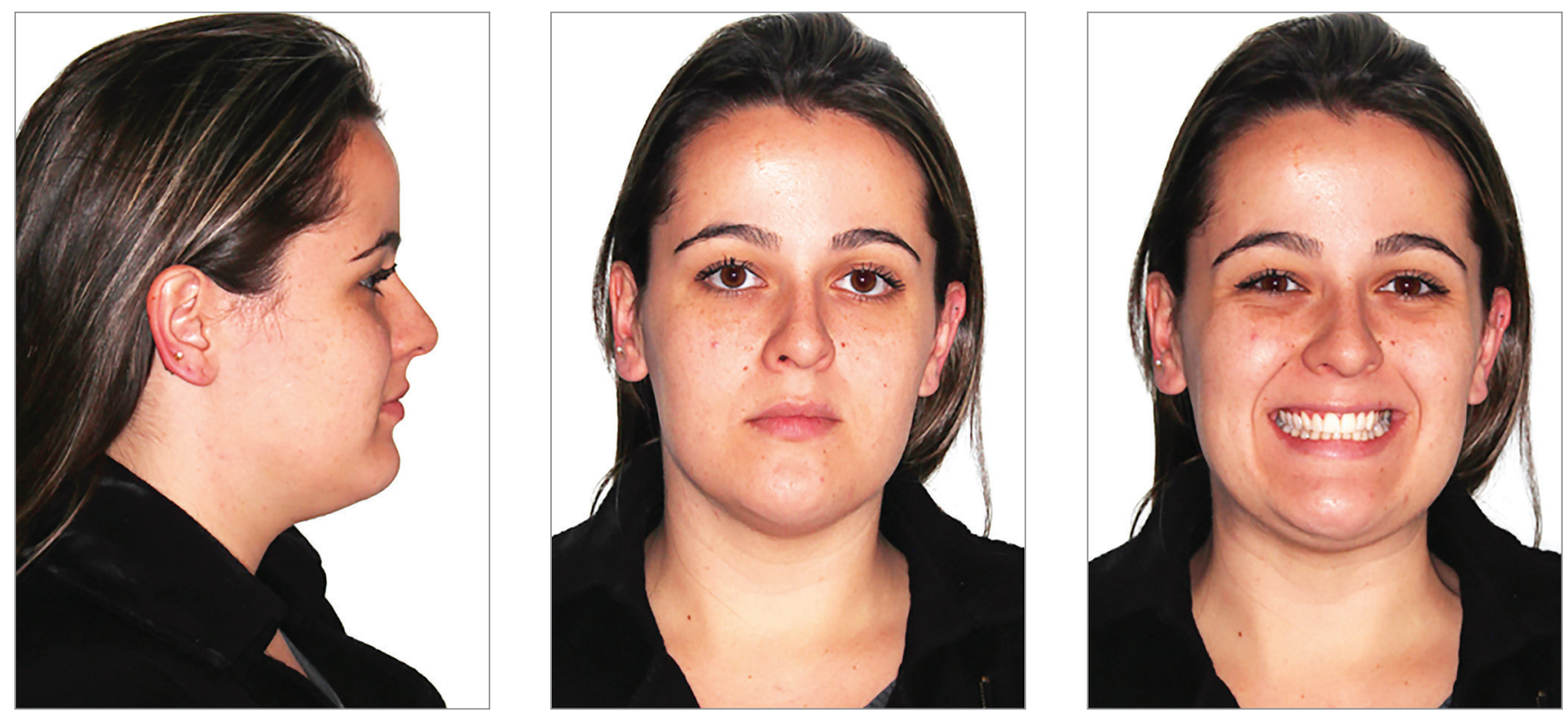

Figure 10 - Initial facial photographs: harmonic profile and proportional face thirds. Smiling photo shows excessive buccal corridors, particularly on left side.


Figure 11 - Initial occlusal photographs; moderate crowding in mandibular arch due to constriction caused by the maxilla. Note the lingual inclination of left posterior teeth in maxillary arch.
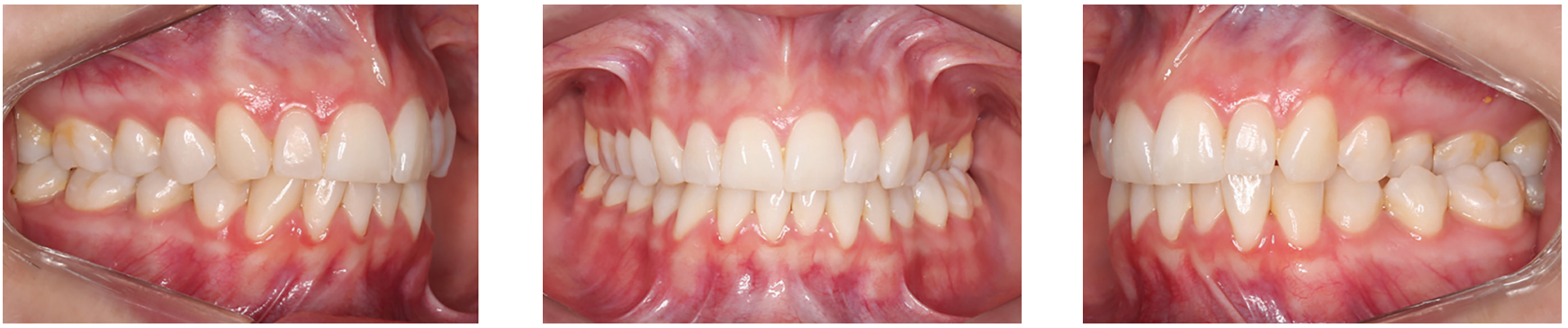

Figure 12 - Initial intraoral photographs: good occlusal relationship on the right side and edge-to-edge relationship of left canines (Class II); left superior buccal segment in crossbite.

tion because of increased mechanical resistance. After 44 activations, at a total of $8.8 \mathrm{~mm}$ screw opening, the MSE was removed for the placement of another expander, a common practice depending on case severity. At this time, crossbite was still present (Fig 19). However, instead of using another MSE and continuing with pure skeletal expansion, we decided to place a conventional tooth-borne Hyrax expander for two reasons: circummaxillary sutures had already been mobilized, and, therefore, skeletal gains should be preserved; and we would like to ensure buccal inclination of maxillary left posterior teeth to optimize future orthodontic treatment. At this point, the patient had already reported important improvement of sleep quality, with facilitated nose breathing and reduction of rhinitis episodes, frequent in the past. 


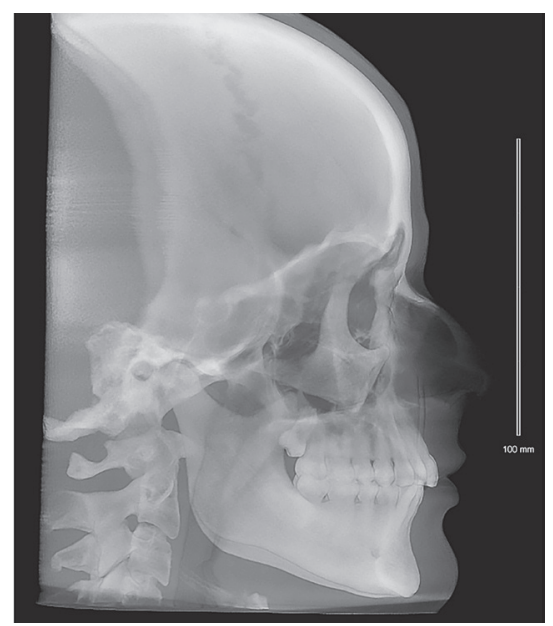

Figure 13 - Lateral radiograph obtained from CBCT shows harmonic maxillomandibular skeletal relationship and satisfactory position of maxillary and mandibular incisors: note that mandibular ramus heights are asymmetric.

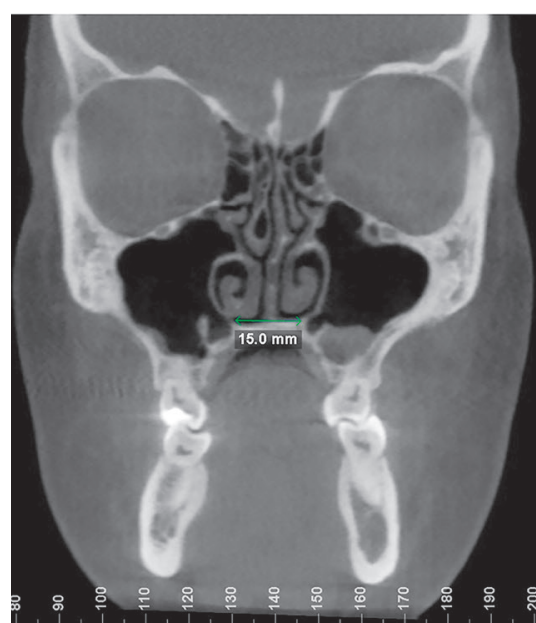

Figure 14 - Coronal CBCT slice at the level of maxillary first molars shows excessive palatal in clination of these teeth; tongue is at a low position; measurement indicated maxillary constric tion and, consequently, nasal cavity constriction.

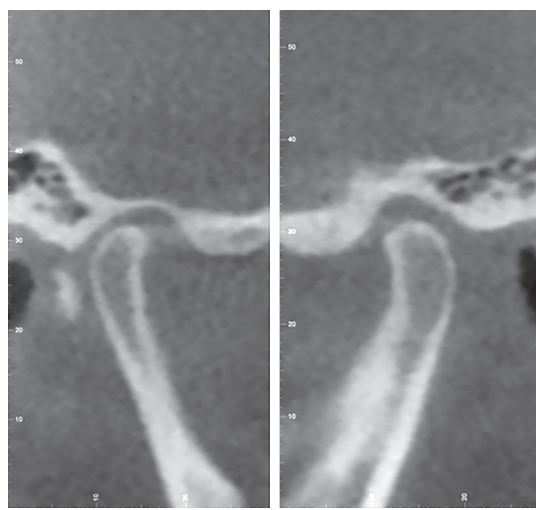

Figure 15 - Sagittal slice shows incorrect position of condyles into articular fossa, especially on the right side (contralateral to the posterior crossbite)

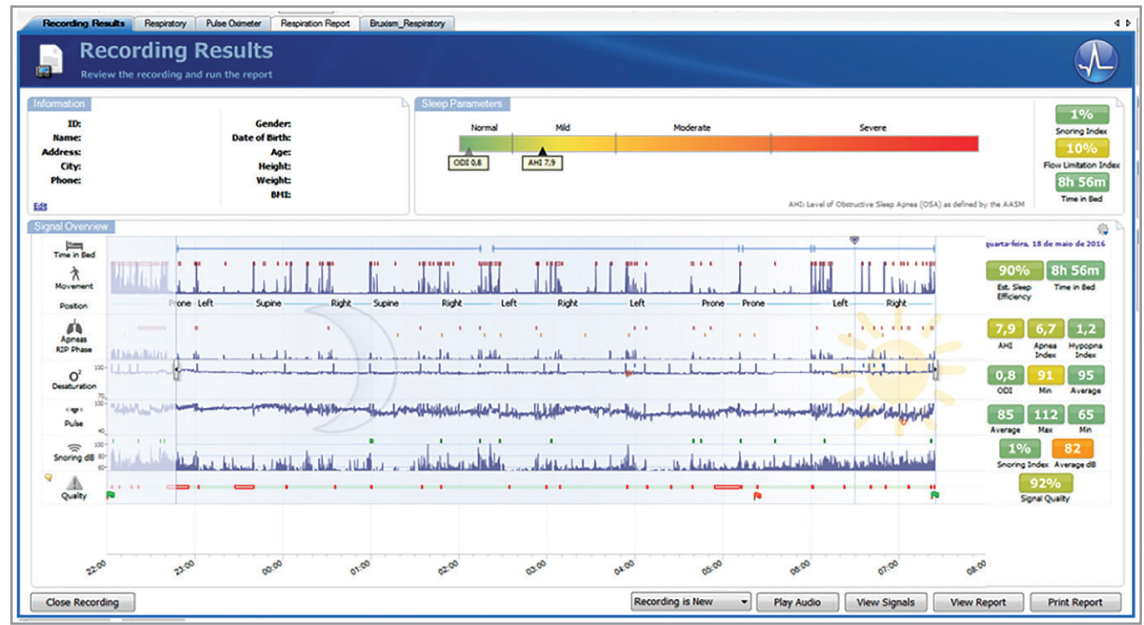

Figure 16 - Baseline in-home polysomnography shows an AHI of 7.9, defined as mild OSAS; despite that, patient has good oxygen saturation along the night.

An $8.8 \mathrm{~mm}$ expansion at the palatal suture may be classified as substantial, as mean opening in conventional expansion in growing patients is usually around 4 to $5 \mathrm{~mm}$.

On the same day the MSE was removed, to eliminate any possibility of relapse, an $11 \mathrm{~mm}$ Hyrax expander was delivered. The bands were placed onto the first molar, and a palatal wire extended to the first premolar on both sides. We continued the protocol of two daily activations until the desired inclination of the left maxillary posterior teeth was achieved. The increase of interdental diastema was clear during the activation period, confirming the skeletal changes.
As unilateral expansion is not feasible, it was necessary to overcorrect the right side until there was buccal crossbite, so that the ideal inclination was achieved in the opposite side (Fig 20). Activations continued until the total expansion was $7 \mathrm{~mm}$, when the expander was tied-out (Fig 21).

Facial photographs after expansion showed decreased buccal corridor display and correction of the lower midline shift at centric occlusion, which confirmed that the mandible was in fact deviated at maximum intercuspation before expansion (Fig 22). Post-expansion CT scan confirmed the opening of the palatal suture (Fig 23) and also showed a more 


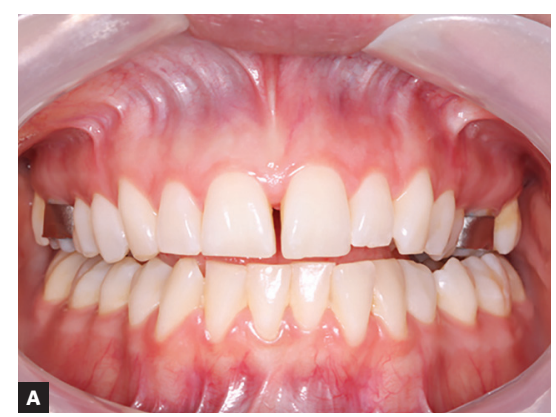

Figure 17 - Photograph taken after 20 activations ( $4 \mathrm{~mm}$ ); interincisal diastema confirms suture opening. Discrete anterior open bite appears due to an overjet reduction of the posterior teeth in crossbite, which generates premature occlusal contacts.

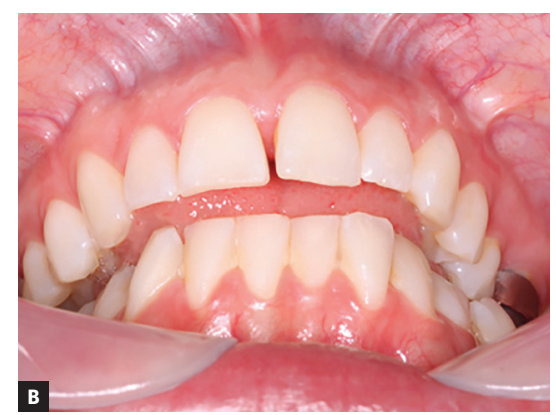

Figure 18 - Maxillary occlusal photograph taken after 34 activations $(6.8 \mathrm{~mm})$. Absence of tooth or alveolar bone tipping as left posterior teeth still show palatal inclination.

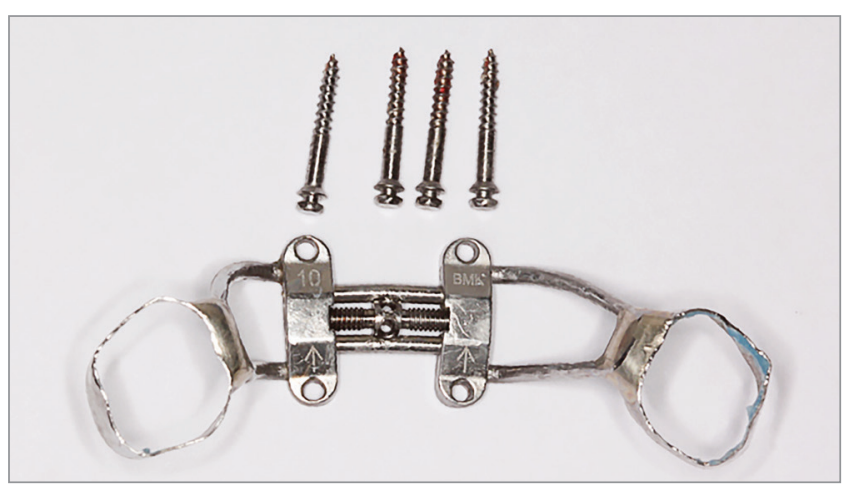

Figure 19 - Photograph taken during MSE removal, after 44 activations $(8.8 \mathrm{~mm})$; high mechanical resistance bent expander built-in support wires; MI with no deformation when removed are signs of ideal progression of the expansion.

favorable buccolingual inclination of the left posterior teeth and an increase on the nasal cavity floor (Fig 24). However, the greatest treatment benefit was probably the one revealed by post-expansion polysomnography: a reduction of the AHI from 7.9 to 1.5. There was also a substantial improvement of clinical symptoms (Fig 25). It is important to inform that no other concurrent therapy for the breathing issue was delivered and that the patient's body mass index remained the same throughout the treatment.

The Hyrax expander would be held in place for the next four months to achieve satisfactory suture ossification. After 3 months of inferior fixed appliance therapy, the inclination of posterior teeth was very improved and almost all the crowding was solved, helping to close the anterior bite back to its baseline status. We believe that the expansion made on the mandibular arch to alleviate the crowding has a better relapse prognosis, because the maxillary arch was skeletally expanded with MARPE creating overjet for lower intercanine width increase. When the Hyrax expander is to be removed, teeth that were overcorrected during expansion on the right side will naturally return to the ideal position, due to muscular activity. After the bones are placed in a favorable transverse position, the case became simple to solve using corrective orthodontic treatment and Class II elastics on the left side. Any other treatment alternative, even using the most sophisticated biomechanics, would be challenged by the lower midline deviation. Even so, the treatment time would be increased and the condyles would remain in an unfavorable position.

Another promising application of this technique may be for Class II hyperdivergent patients, who often present with maxillary transverse deficiency. According to Buschang et al, ${ }^{31,32}$ the best treatment in these cases is true mandibular counter-clockwise rotation. Using MARPE, intrusion of maxillary molars may be executed immediately after maxillary expansion, which promotes counterclockwise rotation of the mandible improving the sagittal relationship. For that purpose, it is enough to remove the bars that hold the expander to the bands after the expansion active retention period. The expander itself will promote transverse retention while it is used for skeletal anchorage to promote posterior maxillary intrusion. In such cases, MI should also be placed in the mandibular arch to avoid compensatory extrusion of the antagonist teeth. 

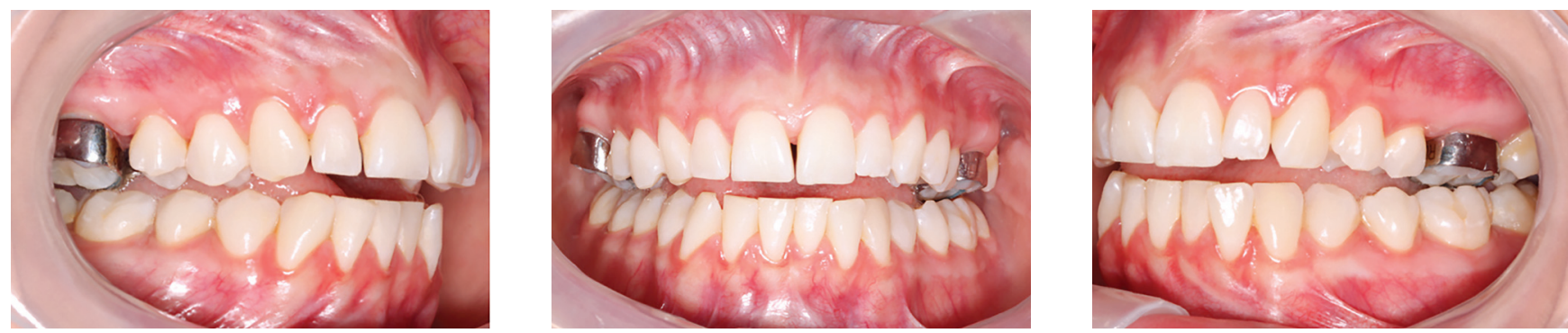

Figure 20 - Intraoral photographs after expansion. Spaces created by the expansion were distributed along maxillary arch. When manipulated to centric occlusion, a substantial transverse increase was evident and the posterior crossbite corrected. Following the expander removal after the recommended retention time right posterior teeth will return to their adequate inclination. A broader maxillary arch allows for the expansion of mandibular arch, which was also constricted.

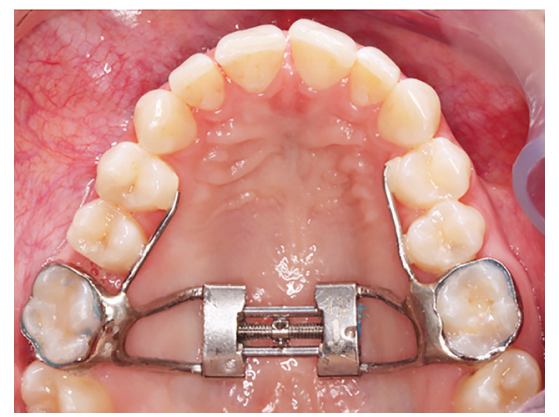

Figure 21 - Occlusal photo taken at Hyrax tielace; smaller expansion on left side, limited by crossbite occluding forces. Left posterior teeth aligned to canine and second molar, which reduces time of treatment with fixed appliance.
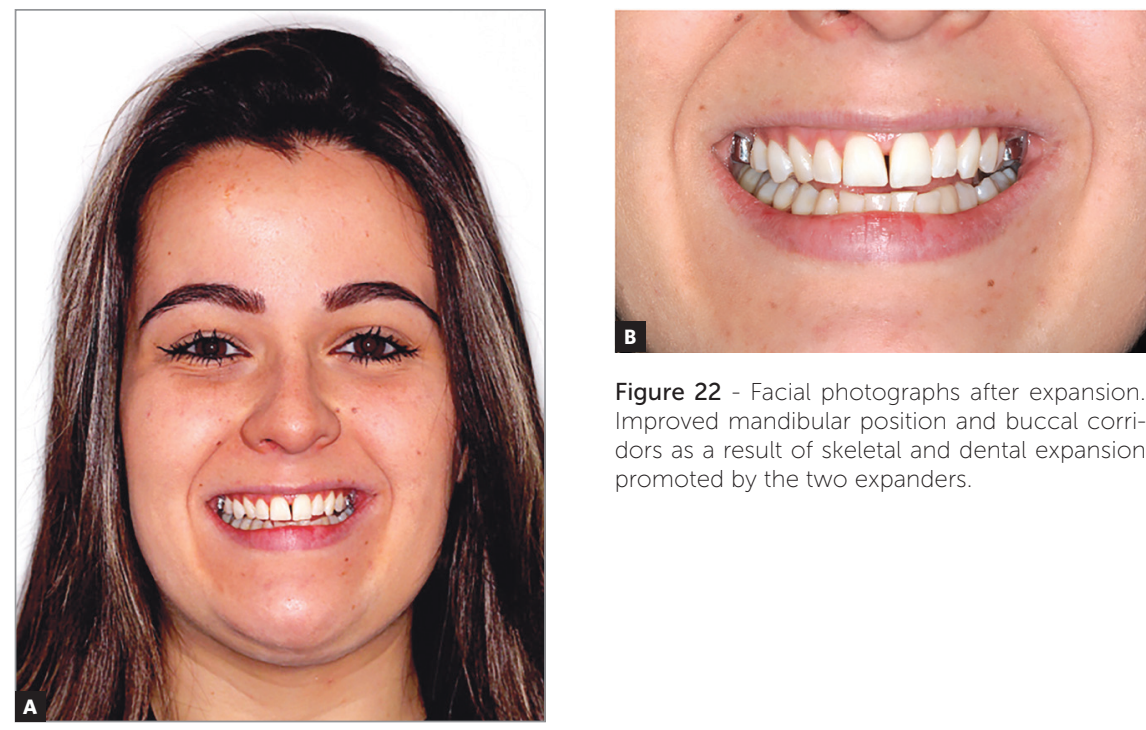

Figure 22 - Facial photographs after expansion Improved mandibular position and buccal corridors as a result of skeletal and dental expansion promoted by the two expanders.
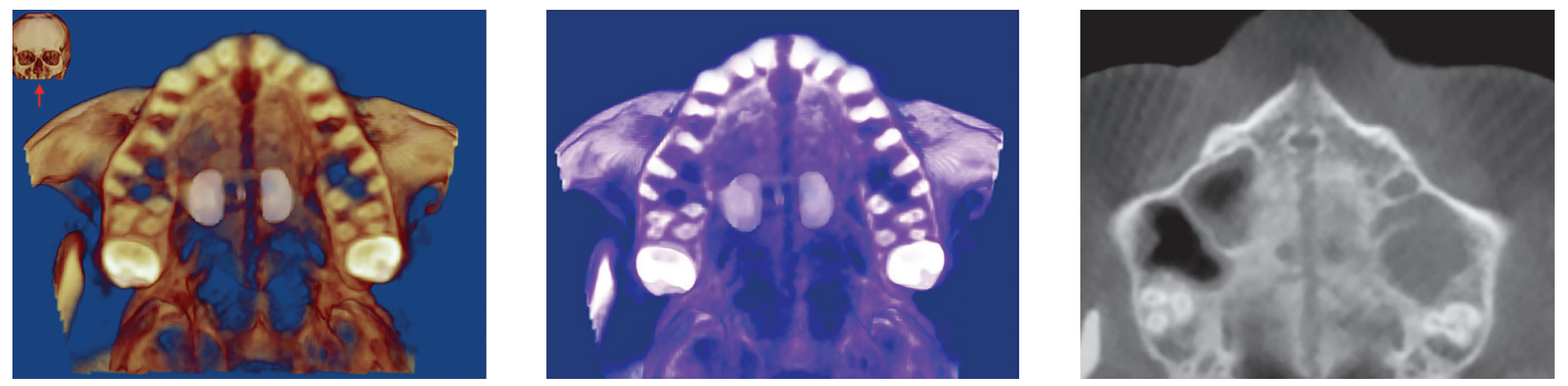

Figure 23 - CBCT slices show homogenous suture opening along anterior and posterior regions and uniform separation of the hemimaxillae.

\section{DISCUSSION}

Embryologic formation and development of the midpalatal suture are thoroughly described in the literature, particularly in histological studies of human specimens. ${ }^{33}$ Medial borders of the hemimaxillae, which grow toward each other until they are mechanically interlocked, progress along the following postnatal development stages: synfibrosis, broad distance between parallel borders; synarthrosis, narrower sinuous course; synostosis, complete interdigitation. ${ }^{34}$ 


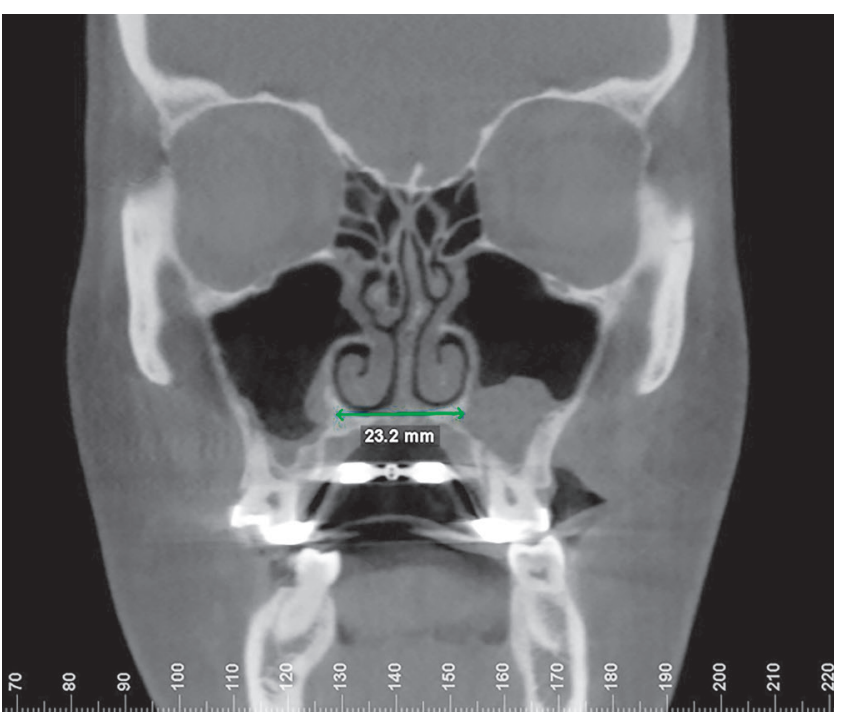

Figure 24 - Coronal slice after expansion shows more favorable buccolingual inclination (torque) of posterior maxillary teeth. Also, nasal cavity floor is $23.2 \mathrm{~mm}$ wide, larger than at baseline $(15 \mathrm{~mm})$. Wax-bite registration was sent to the radiologic laboratory, but the CBCT scan was obtained at maximal intercuspation, suggesting that posterior left crossbite is still present. There was no reason to irradiate the patient again.
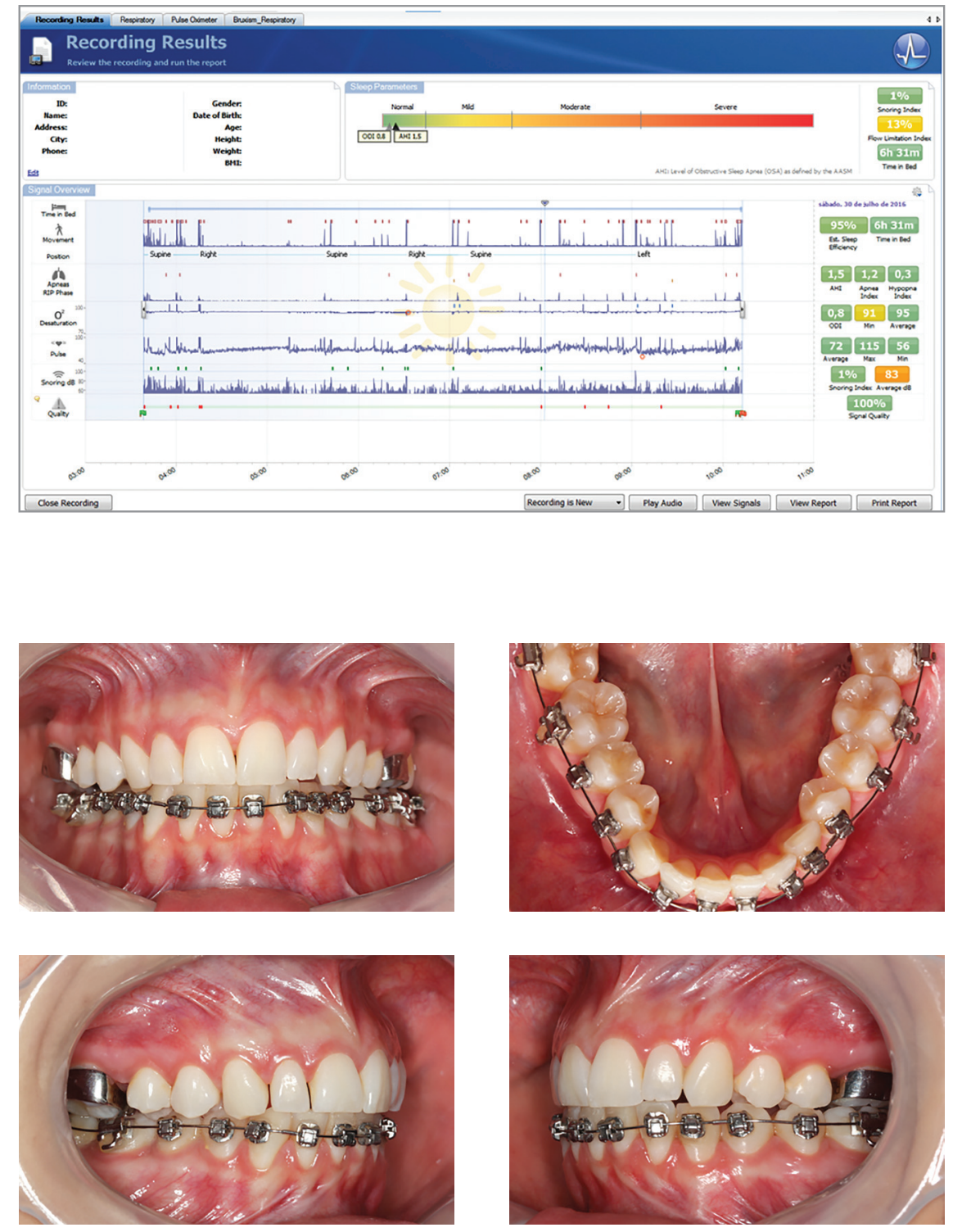

Figure 25 - Post-expansion in-home polysomnography depicted an $\mathrm{AHI}$ of 1.5, a substantial reduction from baseline value of 7.9. Patient presented a more homogeneous breathing pattern during sleep. Clinical symptoms have also improved significantly.
Figure 26 - Photographs three months after inferior fixed appliance delivery. Note anterior overbite improvement, matching of the dental midlines and almost complete crowding dissolution. 


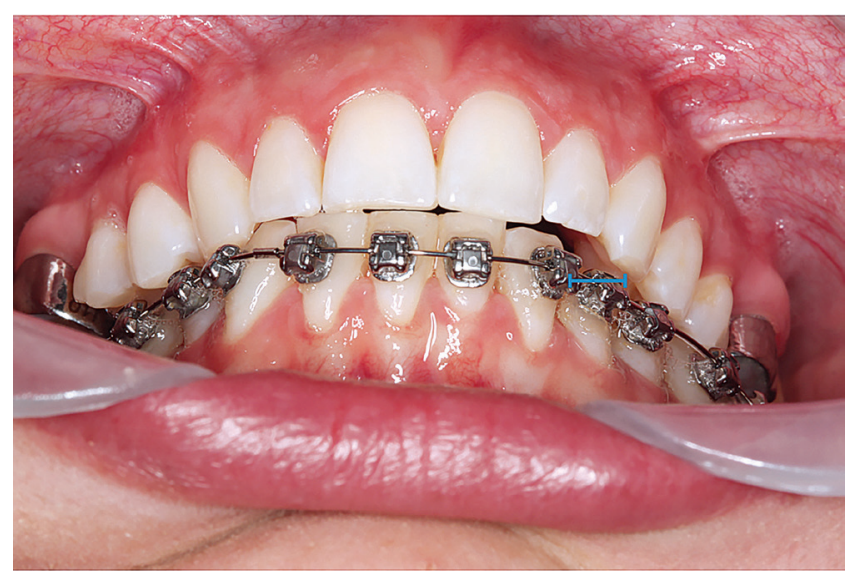

However, the age at full suture ossification (synostosis) has not been definitely determined in the literature. Recent histological studies revealed that only the anterior third of the suture was ossified in human beings older than 70 years, although ossification appeared complete on radiographs. ${ }^{35}$ In those samples, connective tissue was still found in the posterior regions. Such studies support the theory that the midpalatal suture may be the only cranial suture that does not achieve full ossification because of the constant mechanical stress that is applied to it. ${ }^{35,36}$ Histological studies have demonstrated that caution should be taken when defining the stage of ossification using imaging exams. ${ }^{35,37}$

Occlusal radiographs or CBCT should be requested to confirm MARPE success, defined by midpalatal suture opening, because not all cases display an interincisal diastema. However, if the diastema is created, as in the case here reported, suture split and skeletal expansion of the maxilla are evident. It remains unclear why few MARPE cases fail, but it is believed that differences in calcification patterns of the midpalatal suture and craniofacial architecture (higher resistance) are contributing factors..$^{25,38}$

As mechanical forces are distributed into the palate by the MI's, the stress on teeth and supporting structures is understated, which might reduce side effects such as gingival recession and buccal bone dehiscence..$^{20,27,30}$ A clinical study that followed up 69 young adults that underwent MARPE did not find any clinically significant side effects. ${ }^{25}$ Other stud-
Figure 27 - The overjet created on the left cuspids will allow for an increase on the intercanine distance in the mandibular arch, completing its ideal alignment. On the right side, the upper cuspid will also present with some overjet when its torque is corrected.

ies of conventional palatal expansion in young adults without MI have warned about the risk of side effects. ${ }^{23,39}$ Lin et a ${ }^{40}$ recently conducted a direct comparison of MARPE and conventional expansion (mean age $18.1 \pm 4.4$ years) and found that MARPE was more orthopedically efficient and had a lower rate of dentoalveolar side effects. This initial data may be suggestive of evidence, which should be further investigated in randomized clinical trials. Moreover, the effect of MARPE is basically orthopedic, because forces are applied directly to the bone; therefore, there is no need of overcorrection. In conventional expansion, however, overcorrection is recommended because of the orthodontic effects (buccal tipping), which may often lead to relapse. ${ }^{19,41}$ According to Haas, ${ }^{14}$ midpalatal suture rupture takes place after the third or fourth complete turn, at a screw opening of about 3 to $4 \mathrm{~mm}$, because of tooth inclination. When using MARPE, suture split happens sooner, usually still in the second week of activation, because there is less tooth tipping.

A new MSE has been recently developed to incorporate some changes that increase efficiency and treatment predictability. "MSE new design" uses $1.8 \mathrm{~mm}$ diameter MI's and has a robust wrench-type activation key. These changes added greater resistance to both the MI's and jackscrew. It should be indicated in patients that higher resistance of the circummaxillary sutures is expected.

Several MARPE techniques, using various designs, are available. Some expanders are supported 
only by MI (palatal distractors), but most have a hybrid design and are supported by both MI and teeth. A technique developed at Yonsei University uses four MI, two of which in the anterior palate, measuring $1.8 \mathrm{~mm}$ in diameter, and four teeth for anchorage. ${ }^{25}$ It must be kept in mind that different techniques, with differences particularly in MI and expander positioning, have different outcomes.

It has been demonstrated that the dimensions of the nasal cavity increase in growing patients as a result of RPE, and that upper airway resistance may be reduced in the short and long terms. ${ }^{42,43}$ Other studies within several medical specialties have gone further and demonstrated that RPE is efficient to treat pediatric patients with OSAS. Orthodontists should be thoroughly familiar with these longitudinal studies, so that they can give up-to-date information to their patients, as well as to their colleagues in the multidisciplinary team required for the treatment of this syndrome. ${ }^{44-47}$

A recent study found a significant reduction of $56.2 \%$ of the AHI of adult patients that underwent SARPE, as well as significant improvements of OSAS clinical symptoms. ${ }^{48}$ In the same line of thought about MARPE, we may be looking at an interesting treatment option for patients with OSAS, which, however, precludes the use of invasive osteotomies. Although the patient reported here had mild apnea, we currently know that OSAS is progressive, particularly because of the loss of muscle tone and the accumulation of fat in the cervical region as individuals grow older. ${ }^{49}$ Our patient is still very young, but, at a more advanced age, the condition might deteriorate. In her current condition, as a result of treatment, we might expect her to be able to control OSAS in the future with the help of myofunctional therapy to strengthen the oropharyngeal muscles. ${ }^{50}$ MARPE efficacy for this purpose remains to be proven, and it should be determined to which groups of patients, with different OSAS etiologies, this therapy would be most beneficial. However, this treatment may have a high impact on individual quality of life and public health, because moderate/severe OSAS has an estimated prevalence of $23.4 \%$ (95\% CI, 20.9-26.0) among women and $49.7 \%$ (95\% CI, 46.6-52.8) among men (mean age 57 years), which results in substantial costs for the public and private health care systems. ${ }^{51}$
Sufficient evidence has been already gathered to suggest that all orthodontic patients, adult or pediatric, should undergo an evaluation of the risk of OSAS using validated questionnaires, as a form of screening. ${ }^{52}$ Studies in sleep medicine have increasingly highlighted the importance of the orthodontist in the early diagnosis of this syndrome, because the oral cavity has several signs that potentially indicate an increased risk of this syndrome, such as the Mallampati classification. This positioning is even more important in pediatric populations, because the orthodontist is one of the first professionals to carefully assess facial growth and the oral cavity, usually at the age of 6 or 7 years old. ${ }^{53}$ If diagnosed and approached correctly at this early age by a multidisciplinary team, serious problems such as cardiologic and metabolic sequelae could be avoided, which OSAS would probably lead to if undiagnosed. ${ }^{54}$

No severe complications of MARPE have been reported in the literature. The most frequent complication is the inflammation and hyperplasia of the mucosa around the MI, usually associated with inadequate local hygiene. A significant amount of time should be spent to orientate the patient about hygiene importance, using all the tools to optimize it (dental brush and water jet). In cases where mechanical control is not sufficient, a chemical method can be temporarily employed (usually chlorhexidine rinse or gel). If inflammation affects only one MI, it should be removed, and the treatment may progress normally. Hyperplasia may also occur when there is not enough distance from the expander and/or its wires to the mucosa, usually associated with local pain. ${ }^{25}$ In patients with slow bone remodeling, such as those with type II diabetes, additional care should be taken to avoid buccosinusal communication after MI removal, as bone neoformation takes longer. Other systemic conditions should be carefully assessed and might contra-indicate the therapy. One of the limitations of this technique is associated with very narrow and high-arched palates, which hinders MSE vertical positioning and reduces the success rate of the treatment.

To our knowledge, this is the first case report to demonstrate non-surgical resolution of maxillary transverse deficiency associated with OSAS in an adult patient, evaluated in the short term. 


\section{CONCLUSION}

Recent evidence suggests that non-surgical palatal expansion, assisted by microimplants, is achievable and predictable in young adults. No concrete evidence has shown that the palatal suture is completely fused at the end of facial growth, which makes this treatment theoretically applicable at any age and phase of life.

REFERENCES

1. Kurol J, Berglund L. Longitudinal study and cost-benefit analysis of the effect of early treatment of posterior cross-bites in the primary dentition. Eur J Orthod 1992:14(3):173-9.

2. Silva Filho OG, Santamaria M Jr, Capelozza Filho L. Epidemiology of posterior crossbite in the primary dentition. J Clin Pediatr Dent. 2007:32(1):73-8.

3. Modeer T, Odenrick L, Lindner A. Sucking habits and their relation to posterior cross-bite in 4-year-old children. Scand J Dent Res. 1982;90(4):323-8.

4. Lione R, Franchi L, Huanca Ghislanzoni LT, Primozic J, Buongiorno M, Cozza P. Palatal surface and volume in mouth-breathing subjects evaluated with three-dimensional analysis of digital dental casts-a controlled study. Eur J Orthod. 2015 Feb; 37(1):101-4.

5. Moss ML. The functional matrix hypothesis revisited. 1. The role of mechanotransduction. Am J Orthod Dentofacial Orthop. 1997 July:112(1):8-11.

6. Bayram S, Basciftci FA, Kurar E. Relationship between P561T and C422F polymorphisms in growth hormone receptor gene and mandibular prognathism. Angle Orthod. 2014 Sept;84(5):803-9.

7. McNamara JA Jr, Lione R, Franchi L, Angelieri F, Cevidanes LH, Darendeliler $M A$, et al. The role of rapid maxillary expansion in the promotion of oral and general health. Prog Orthod. 2015:16:33.

8. Aloufi F, Preston CB, Zawawi KH. Changes in the upper and lower pharyngeal airway spaces associated with rapid maxillary expansion. ISRN Dent. 2012;2012:290964
Microimplant-assisted RPE in adults, in addition to an efficient solution for maxillary transverse deficiency in a substantial number of patients, seems to have an important impact on the reduction of upper airway resistance. The robust skeletal anchorage provided by the palatal expander offers novel mechanical possibilities for the treatment of a wide range of malocclusions.
9. De Rossi M, De Rossi A, Hallak JE, Vitti M, Regalo SC. Electromyographic evaluation in children having rapid maxillary expansion. Am J Orthod Dentofacial Orthop. 2009:136(3):355-60.

10. Alexander NS, Schroeder JW Jr. Pediatric obstructive sleep apnea syndrome. Pediatr Clin North Am. 2013;60(4):827-40.

11. Vidya VS, Sumathi FA. Rapid maxillary expansion as a standard treatment for obstructive sleep apnea syndrome: a systematic review. J Dental Med Sci. 2015:14:51-5.

12. Lagravere MO, Heo G, Major PW, Flores-Mir C. Meta-analysis of immediate changes with rapid maxillary expansion treatment. J Am Dent Assoc. 2006:137(1):44-53

13. McNamara JA. Maxillary transverse deficiency. Am J Orthod Dentofacial Orthop. 2000:117(5):567-70

14. Haas AJ. The treatment of maxillary deficiency by opening the midpalatal suture. Angle Orthod. 1965 July:35:200-17.

15. Franchi L, Baccetti T, Lione R, Fanucci E, Cozza P. Modifications of midpalatal sutural density induced by rapid maxillary expansion: a lowdose computed-tomography evaluation. Am J Orthod Dentofacial Orthop. 2010:137(4):486-8; discussion 12A-13A.

16. Liu S, Xu T, Zou W. Effects of rapid maxillary expansion on the midpalatal suture: a systematic review. Eur J Orthod. 2015;37(6):651-5.

17. Melsen B, Melsen F. The postnatal development of the palatomaxillary region studied on human autopsy material. Am J Orthod. 1982:82(4):329-42. 
18. Persson $\mathrm{M}$, Thilander $\mathrm{B}$. Palatal suture closure in man from 15 to 35 years of age. Am J Orthod. 1977:72(1):42-52

19. Garrett BJ, Caruso JM, Rungcharassaeng K, Farrage JR, Kim JS, Taylor GD Skeletal effects to the maxilla after rapid maxillary expansion assessed with cone-beam computed tomography. Am J Orthod Dentofacial Orthop. 2008 July:134(1):8-9

20. Garib DG, Henriques JF, Janson G, de Freitas MR, Fernandes AY. Periodontal effects of rapid maxillary expansion with tooth-tissue-borne and tooth-borne expanders: a computed tomography evaluation. Am J Orthod Dentofacial Orthop. 2006;129(6):749-58.

21. Stuart DA, Wiltshire WA. Rapid palatal expansion in the young adult: time for a paradigm shift? J Can Dent Assoc. 2003;69(6):374-7

22. Handelman CS, Wang L, BeGole EA, Haas AJ. Nonsurgical rapid maxillary expansion in adults: report on 47 cases using the Haas expander. Angle Orthod. 2000;70(2):129-44

23. Northway WM, Meade JB Jr. Surgically assisted rapid maxillary expansion: a comparison of technique, response, and stability. Angle Orthod. 1997:67(4):309-20

24. Carlson C, Sung J, McComb RW, Machado AW, Moon W. Microimplantassisted rapid palatal expansion appliance to orthopedically correct transverse maxillary deficiency in an adult. Am J Orthod Dentofacial Orthop. 2016;149(5):716-28.

25. Choi SH, Shi KK, Cha JY, Park YC, Lee KJ. Nonsurgical miniscrew-assisted rapid maxillary expansion results in acceptable stability in young adults. Angle Orthod. 2016 Sept;86(5):713-20

26. Lee HK, Bayome M, Ahn CS, Kim SH, Kim KB, Mo SS, et al. Stress distribution and displacement by different bone-borne palatal expanders with micro-implants: a three-dimensional finite-element analysis. Eur J Orthod 2014;36(5):531-40

27. MacGinnis M, Chu H, Youssef G, Wu KW, Machado AW, Moon W. The effects of micro-implant assisted rapid palatal expansion (MARPE) on the nasomaxillary complex--a finite element method (FEM) analysis. Prog Orthod. 2014 Aug 29:15:52

28. Reiser GM, Bruno JF, Mahan PE, Larkin LH. The subepithelial connective tissue graft palatal donor site: anatomic considerations for surgeons. Int J Periodontics Restorative Dent. 1996 Apr:16(2):130-7.

29. Berry RB, Budhiraja R, Gottlieb DJ, Gozal D, Iber C, Kapur VK, et al. Rules for scoring respiratory events in sleep: update of the 2007 AASM Manual for the Scoring of Sleep and Associated Events. Deliberations of the Sleep Apnea Definitions Task Force of the American Academy of Sleep Medicine J Clin Sleep Med. 2012 Oct 15:8(5):597-619.

30. Wilmes B, Nienkemper M, Drescher D. Application and effectiveness of a mini-implant- and tooth-borne rapid palatal expansion device: the hybrid hyrax. World J Orthod. 2010 Winter;11(4):323-30.

31. Buschang PH. An interview with Peter H. Buschang. Dental Press J Orthod 2014 Nov-Dec;19(6):26-36

32. Buschang PH, Carrillo R, Rossouw PE. Orthopedic correction of growing hyperdivergent, retrognathic patients with miniscrew implants. J Oral Maxillofac Surg. 2011 Mar;69(3):754-62.

33. Latham RA. The development, structure and growth pattern of the human mid-palatal suture. J Anat. 1971 Jan;108(Pt 1):31-41.

34. Melsen B. Palatal growth studied on human autopsy material. A histologic microradiographic study. Am J Orthod. 1975 July;68(1):42-54.

35. N'Guyen T, Ayral X, Vacher C. Radiographic and microscopic anatomy of the mid-palatal suture in the elderly. Surg Radiol Anat. 2008 Feb;30(1):65-8.

36. Poorsattar Bejeh Mir K, Poorsattar Bejeh Mir A, Bejeh Mir MP, Haghanifar S. A unique functional craniofacial suture that may normally never ossify: a cone-beam computed tomography-based report of two cases. Indian J Dent. 2016 Jan-Mar;7(1):48-50
37. Wehrbein $\mathrm{H}$, Yildizhan $\mathrm{F}$. The mid-palatal suture in young adults. A radiologicalhistological investigation. Eur J Orthod. 2001 Apr;23(2):105-14

38. Lee KJ, Park YC, Park JY, Hwang WS. Miniscrew-assisted nonsurgical palatal expansion before orthognathic surgery for a patient with severe mandibular prognathism. Am J Orthod Dentofacial Orthop. 2010:137(6):830-9

39. Vanarsdall RL Jr. Transverse dimension and long-term stability. Semin Orthod 1999 Sept:5(3):171-80

40. Lin L, Ahn HW, Kim SJ, Moon SC, Kim SH, Nelson G. Tooth-borne vs boneborne rapid maxillary expanders in late adolescence. Angle Orthod. 2015 Mar; 85(2):253-62

41. Basdra EK, Zoller JE, Komposch G. Surgically assisted rapid palatal expansion. J Clin Orthod. 1995;29(12):762-6.

42. Felippe NLO, Silveira AC, Viana G, Kusnoto B, Smith B, Evans CA. Relationship between rapid maxillary expansion and nasal cavity size and airway resistance: short- and long-term effects. Am J Orthod Dentofacial Orthop. 2008 Sept:134(3):370-82

43. Palaisa J, Ngan P, Martin C, Razmus T. Use of conventional tomography to evaluate changes in the nasal cavity with rapid palatal expansion. Am J Orthod Dentofacial Orthop. 2007 Oct;132(4):458-66.

44. Pirelli P, Saponara M, Guilleminault C. Rapid maxillary expansion (RME) for pediatric obstructive sleep apnea: a 12-year follow-up. Sleep Med. 2015 Aug:16(8):933-5

45. Villa MP, Rizzoli A, Miano S, Malagola C. Efficacy of rapid maxillary expansion in children with obstructive sleep apnea syndrome: 36 months of follow-up. Sleep Breath. 2011 May:15(2):179-84.

46. Guilleminault C, Monteyrol PJ, Huynh NT, Pirelli P, Quo S, Li K. Adenotonsillectomy and rapid maxillary distraction in pre-pubertal children, a pilot study. Sleep Breath. 2011 May;15(2):173-7.

47. Machado-Junior AJ, Zancanella E, Crespo AN. Rapid maxillary expansion and obstructive sleep apnea: a review and meta-analysis. Med Oral Pato Oral Cir Bucal. 2016:21(4):e465-9

48. Vinha PP, Eckeli AL, Faria AC, Xavier SP, Mello-Filho FV. Effects of surgically assisted rapid maxillary expansion on obstructive sleep apnea and daytime sleepiness. Sleep Breath. 2016 May:20(2):501-8.

49. Marcus CL, Brooks LJ, Draper KA, Gozal D, Halbower AC, Jones J, et al. Diagnosis and management of childhood obstructive sleep apnea syndrome. Pediatrics. 2012;130(3):e714-55.

50. Camacho M, Certal V, Abdullatif J, Zaghi S, Ruoff CM, Capasso R, et al. Myofunctional therapy to treat obstructive sleep apnea: a systematic review and meta-analysis. Sleep. 2015 May 1;38(5):669-75.

51. Heinzer R, Vat S, Marques-Vidal P, Marti-Soler H, Andries D, Tobback N. et al. Prevalence of sleep-disordered breathing in the general population the HypnoLaus study. Lancet Respir Med. 2015 Apr;3(4):310-8

52. De Luca Canto G, Singh V, Major MP, Witmans M, El-Hakim H, Major PW et al. Diagnostic capability of questionnaires and clinical examinations to assess sleep-disordered breathing in children: a systematic review and meta-analysis. J Am Dent Assoc. 2014 Feb;145(2):165-78.

53. Graf I, Schumann U, Neuschulz J, Höfer K, Ritter L, Braumann B, et al. Sleep-disordered breathing in orthodontic practice: Prevalence of snoring in children and morphological findings. J Orofac Orthop. 2016 Mar;77(2):129-37.

54. Baldassari CM, Mitchell RB, Schubert C, Rudnick EF. Pediatric obstructive sleep apnea and quality of life: a meta-analysis. Otolaryngol Head Neck Surg. 2008 Mar;138(3):265-73. 